Int. J. Electrochem. Sci., 15 (2020) $9902-9916$

International Journal of

ELECTROCHEMICAL

SCIENCE

$\underline{\text { www.electrochemsci.org }}$

\title{
A Thermodynamic Modelling Study of Aqueous Tetra-n-butyl Ammonium Halide Solutions
}

\author{
Li Sun ${ }^{1,2, *}$, Jierong Liang ${ }^{3}$ \\ ${ }^{1}$ Department of Chemical and Biochemical Engineering, Technical University of Denmark, 2800, \\ Kgs. Lyngby, Denmark \\ ${ }^{2}$ College of Mechanical and Electrical Engineering, Hohai University, Changzhou 213022, People's \\ Republic of China \\ ${ }^{3}$ Department of Energy Conversion and Storage, Technical University of Denmark, 2800 Kgs. \\ Lyngby, Denmark \\ *E-mail: 1sun@kt.dtu.dk
}

doi: $10.20964 / 2020.10 .39$

Received: 10 June 2020 / Accepted: 7 August 2020 / Published: 31 August 2020

This work presents a novel model for aqueous electrolyte solutions that extends the Cubic Plus Association Equation of State by combining the Debye-Hückel theory for electrostatic interactions. This model is applied to perform a fluid phase modelling study of aqueous tetra-n-butyl ammonium halide solutions. The interaction parameters between cations/anions and water are evaluated by regression of the experimental mean ionic activity coefficients (MIAC) of the electrolyte. The results show that this novel model correlates reasonably well with the experimental MIAC (for example, the relative average deviations are $6.3 \%$ for the MIAC of tetra-n-butyl-ammonium bromide). The interaction parameters between cations/anions and gas are evaluated by regression of the experimental gas solubilities. The results show that this novel electrolyte model correlates reasonably well with gas solubility (for example, the relative average deviations are $2.9 \%$ for the nitrogen solubility in aqueous tetra-n-butyl-ammonium bromide solutions). For a more complete evaluation of the model, the electrostatic terms, parameter estimation approaches, and salting effects on gas solubility are analysed and discussed in detail.

Keywords: Aqueous Tetra-n-butyl Ammonium Halide Solutions; Electrolyte Equation of State; Debye-Hückel Theory; Hydrophobic Effect

\section{$\underline{\text { FULL TEXT }}$}

(C) 2020 The Authors. Published by ESG (www.electrochemsci.org). This article is an open access article distributed under the terms and conditions of the Creative Commons Attribution license (http://creativecommons.org/licenses/by/4.0/). 